\title{
Selection, characterizations and somatic embryogenesis of Malaysian salt-tolerant rice (Oryza sativa cv. MR219) through callogenesis
}

\begin{abstract}
Salt-tolerant lines of MR219 were produced through somatic embryogenesis from salttolerant callus of Oryza sativa L. cv.MR219 using in vitro selection procedure. Callus was developed aseptically from seeds on MS media supplemented with 2 mg L -1 2, 4-D. Then, callus directly was sub-cultured on MS media with different concentrations of $\mathrm{NaCl}(0,50$, 100,200 , and $300 \mathrm{mM}$ ) to produce salt-tolerant callus. Based on the callus characteristics which are morphological, physiological and biochemical cascades such as proline content, total protein, total soluble sugar, lipid peroxidation, activity of ascorbate peroxidase and catalase, salt-tolerant callus was screened and selected. After 4 months, callus cultured in 50 and $100 \mathrm{mM} \mathrm{NaCl}$ showed yellow color, soft, friable and nodular proliferating. However, callus cultured in 200 and $300 \mathrm{mM} \mathrm{NaCl}$ turn blackish-brown and stiff and acutely-necrotic. The selected salt-tolerant callus was sub-cultured on MS media for somatic embryogenesis. The salt-tolerant plantlets were transferred into pots individually for acclimatization purpose. Salt stress caused significant reduction in water content, fresh and dry weight of callus. The level of total soluble sugar, proline, lipid peroxidation and ascorbate peroxidase significantly increased under salt stress. Salt-tolerant callus indicated high activity of catalase that determined more protection against production of reactive oxygen species. According to growth performance and antioxidant capacity, the plantlets from 50 and $100 \mathrm{mM} \mathrm{NaCl}$, selected as salt-tolerant line. This study suggests the methodology to produce salt-tolerant cultivar of rice which could be a step forward to commercialization.
\end{abstract}

Keyword: Salinity; Antioxidant; Lipid peroxidation; Indica rice MR219; Regeneration 